\title{
Correlation Research of Xinjiang Tourism Industry Structure based on Grey Relational Degree
}

\author{
$\mathrm{Ji} \mathrm{Ma}^{1,2}$, Fangming Qin ${ }^{2, *}$ \\ ${ }^{1}$ The Tourism College, Xinjiang University, Urumqi Xinjiang, 830049, China \\ ${ }^{2}$ School of Economics and Management, Xinjiang University, Urumqi Xinjiang, 830049, China
}

Keywords: Tourism industry structure, Grey correlation, Xinjiang inbound tourism

\begin{abstract}
Tourism industry structure is a complex integrated system, which consists of various sectors of the tourism industry composition. You can use gray correlation analysis on various sectors of the tourism industry correlation analysis factors. The strength of the association decided to cohesion industrial structure, affecting the overall level of tourism industry structure. In this paper, the gray relational analysis of inbound tourism in Xinjiang as the research object, the influence of various factors and income Inbound Tourism Industry Structure in Xinjiang association analysis, and put forward suggestions inbound tourism industry in Xinjiang.
\end{abstract}

\section{Introduction}

With the expansion of the rapid development of China's tourism industry scale and industrial structure, optimize the structure of the tourism industry gradually attention has been paid. Tourism industry structure optimization is to promote the coordinated development of the tourism economy and continuously improve economic efficiency in the process. In this paper, gray correlation calculation of the components of Xinjiang inbound tourism industry based on gray theory analysis, and analysis on the basis of relevance of each of the industrial structure, to grasp the development direction of the Xinjiang tourism industry structure, and reasonable optimization.

\section{Concept definition}

Tourism industry structure is a complex integrated system, the current structure of the tourism industry has not been a unified concept of domestic scholars such as Luo Mingyi, Wang Dawu, Wei Xiaoan, Linnan branches of the tourism industry, who have been defined structure, according to domestic scholars definition of the concept of the tourism industry, the tourism industry structure can be divided into broad and narrow sense. Generalized tourism industry structure is composed of many structures in the tourism sector structure, regional structure of tourism industry, organizational structure, product structure, ownership structure and other components. And in the narrow sense of the tourism industry structure is made tourist attractions, tourist transportation, tourism, catering, tourism accommodation, travel agencies and other key departments. This article refers to the tourism industry structure refers to its narrow concept, and the scope of the study is limited to long-distance transportation, sightseeing, accommodation, catering, sales, entertainment, telecommunications, city traffic, other services in nine areas.

\section{Model building}

\section{Model principle}

Deng Julong gray theory in the late 1970s and early 1980s raised, gray concept is "small data" and "information uncertainty" integrate the two concepts, that is gray, ie "minority uncertainty", it can be said gray system where a few uncertain system. Through the generation of partially known, development, extraction of valuable information to achieve operational behavior of the system, the correct description and effective control of the evolution. The aim is to understand the key relationships between the factors within the system through a certain way to find the most influential 
factors and contradictory relationship. Tourism is a complex integrated system of systems, in addition to the transportation, accommodation, dining, sightseeing, shopping and entertainment subsystems, but also involves a number of other elements of the industrial system, it is difficult to distinguish the relationship between all the elements and each element of each other the extent of the impact on the system. Therefore, the gray system theory can borrow the entire tourism industry as a gray system using gray correlation degree of each system to study the association of each factor with the tourism industry between each other.

\section{Nondimensionalization of data}

Due to the system in different physical meaning or units of various factors, resulting in different dimension data, such data is difficult to compare put together. Hence the need to eliminate the dimensionless raw data into comparable data series. In this paper, $X_{i}(k)=X_{i}(k) / X_{i}(1)$ is used for nondimensionalization of original data. The correlation coefficient is calculated as follows:

$$
\begin{aligned}
X_{0} & =(1,1.1,2.1,2.5,3) \quad X 1 \\
X_{2} & =(1,1.2,1.3,1.4,1.6) \quad X_{3}=(1,1.3,1.2,1.3,1.5) \\
& (1,25,0.8,0.5)
\end{aligned}
$$

\section{Evaluation of sequence of difference}

$$
\Delta i(k)=\left|x_{0}(k)-x_{i}(k)\right|, \Delta i(k)=(\Delta i(1), \Delta i(2), \ldots \Delta i(k))
$$

The absolute difference between $X_{i}$ and $X_{0}$ in each moment as follows:

\begin{tabular}{cccccc}
\hline Serial number & 1 & 2 & 3 & 4 & 5 \\
\hline$\Delta_{1}=\left|x_{0}(k)-x_{1}(k)\right|$ & 0 & 0.3 & 0.9 & 1.2 & 1.5 \\
\hline$\Delta_{2}=\left|x_{0}(k)-x_{2}(k)\right|$ & 0 & 0.1 & 0.8 & 0.9 & 1.4 \\
\hline$\Delta_{3}=\left|x_{0}(k)-x_{3}(k)\right|$ & 0 & 0.2 & 0.85 & 1.7 & 2.5 \\
\hline
\end{tabular}

\section{Acquire maximum and minimum value of two levels}

$M=\max \Delta i(k), \quad m=\min \Delta i(k), \quad \mathrm{M}, \mathrm{m}$ represents the maximum and minimum value at each moment.

\section{Calculate correlation coefficient}

At moment $k$, the correlation coefficient $x_{i}(k)$ between master sequence $x_{0}(k)$ and sub-subsequence can be calculated as the following formation

$$
r_{0 i}(k)=\frac{m+\rho M}{\Delta i(k)+\rho M}
$$

Where, $\rho$ is resolution ratio, means to weaken the distortion caused by too much absolute difference between the maximum value, increase the significance difference between the correlation coefficient, normally can be $0.1-0.5$. In this paper, $\rho$ is 0.5 。

$$
r_{1(1)}=\frac{0+0.5 * 2.5}{0+0.5 * 2.5}=1
$$

It can be calculated by the formula ${ }^{1(1)}=1$

$$
r_{1(2)}=\frac{0+0.5 * 2.5}{0.3+0.5 * 2.5}=0.806
$$

It can be calculated by the formula $r_{1(2)}=0.806$ 


$$
r_{1(3)}=\frac{0+0.5 * 2.5}{0.9+0.5 * 2.5}=0.581
$$

It can be calculated by the formula ${ }^{r_{1(3)}}=0.581$

$$
r_{1(4)}=\frac{0+0.5 * 2.5}{1.2+0.5 * 2.5}=0.521
$$

It can be calculated by the formula ${ }^{r_{1(4)}}=0.521$

$$
r_{1(5)}=\frac{0+0.5 * 2.5}{1.5+0.5 * 2.5}=0.455
$$

It can be calculated by the formula $r_{1(5)}=0.455$

\section{Acquire degree of association}

Correlation coefficient more, information is too scattered and not easy to compare, for which it is necessary to integrate a number of correlation coefficient value, which is related degree. Correlation is the correlation coefficient for each moment of each sub-sequence with the parent sequence mean that $r_{0 i}=\frac{1}{N} \sum_{k=1}^{N} r_{0 i}(k)$, in which $r_{0 i}$ is the association degree of $i$ and $0, N$ is the number of subsequence.

\section{Data processing}

Inbound Tourism Industry structure includes travel industry, hotel industry, tourism, transportation, travel accommodation industry, tourist attractions, tourism and entertainment goods and other industries. According to the Xinjiang Statistical Yearbook data we will long transportation, sightseeing, accommodation, catering, marketing, entertainment, telecommunications, city traffic, other services 9 kinds of factors as the research object, namely the subsequence $X_{1}-X_{9}$. $X_{1}$ Long-distance transportation, $X_{2}$ - tour, $X_{3}$ - accommodation, $X_{4}$-catering, $X_{5}$ - sales of merchandise, $X_{6}$ - entertainment, $X_{7}$ - telecommunications, $X_{8}$-transportation for the city, $X_{9}$-other services. And the number of tourism revenue over the year change column to the parent sequence $X_{0}$. Analysis of these differences in the degree of association of nine total factor sequence and tourism foreign exchange earnings between time series, can be determined the contribution of different sectors of the tourism industry.

Xinjiang inbound tourism data by the standardization process, and brought it into the differencing sequence formula, calculated inbound tourism sectors Xinjiang poor series, and calculate on this basis to give Xinjiang inbound tourism industry sector relationships and gray correlation coefficient table. Gray Correlation and its various departments and the correlation between total revenue comparison, the following table.

Table 1. Xinjiang various departments inbound tourism industry gray correlation and income proportion table

\begin{tabular}{ccc}
\hline Metric & Correlation degree & Average revenue Proportion for 10 years \\
\hline Long-distance transportation & $0.8710(3)$ & $27.54(2)$ \\
\hline Tourism & $0.7487(8)$ & $3.83(6)$ \\
\hline Accommodation & $0.8751(2)$ & $8.77(3)$ \\
\hline Catering & $0.8178(6)$ & $6.03(5)$ \\
\hline Merchandise sales & $0.8421(4)$ & $37.2(1)$ \\
\hline Entertainment & $0.7285(9)$ & $3.49(7)$ \\
\hline Telecommunication & $0.9378(1)$ & $2.53(8)$ \\
\hline Urban transport & $0.7932(7)$ & $2.33(9)$ \\
\hline Other services & $0.8247(5)$ & $8.28(4)$ \\
\hline
\end{tabular}




\section{Xinjiang tourism industry structure analysis and optimization suggestions}

\section{Xinjiang tourism industry structure analysis}

Table 1 shows that the various departments of Xinjiang inbound tourism industry association of post and telecommunications up to 0.9378 , the lowest to 0.7285 entertainment related. The overall correlation degree were above 0.7. Associate degree from large to small as follows: postal and telecommunications $>$ Accommodation $>$ long-distance traffic $>$ merchandising $>$ Other Services $>$ Dining> Local Transportation> Tour> Entertainment. From the 2004-2013 average of 10 years for each sector can be seen in the proportion of revenue accounted for the proportion of total inbound tourism revenue highest sales of goods accounted for $37.2 \%$, the lowest proportion was 2.33 percent city traffic. Rose from large to small as follows: merchandise sales $>$ long distance traffic $>$ Accommodation $>$ Other Services $>$ Dining $>$ Tour $>$ Entertainment $>$ posts and telecommunications $>$ city traffic.

Tourism revenue has not absolute advantage, while inbound tourism foreign exchange earnings in construction, transport (long-distance traffic, city traffic), accommodation, catering, sales in these sectors accounting for $81.87 \%$ of the proportion of foreign exchange earnings in tourism, sightseeing, entertainment, telecommunications, other services sectors are relatively low proportion of foreign exchange, accounting for only $18.13 \%$. From the point of view of tourism demand elasticity, high elasticity of demand merchandising, entertainment, telecommunications sector in addition to merchandise sales, earning in other sectors accounted for a lower proportion, the ratio was $14.3 \%$. Low elasticity of demand for transportation, accommodation, meals, sightseeing in tourism sector accounts for a higher proportion of foreign exchange earnings, the ratio was $48.5 \%$, especially the highest proportion of the traffic. Visible, Xinjiang inbound tourism industry structural imbalance, development irrational industrial structure greater vulnerability.

Xinjiang inbound tourism industry, the association of post and telecommunications in the first row, but only 2.53\% of total tourism revenue, ranking eighth. Thus, although such a rapid development in information technology today, posts and telecommunications in the tourism industry occupies a very important position, but the development of Xinjiang Communications Posts in e-commerce, digital tourism, tourist information publishing, travel and other aspects of wisdom far behind, strengthen post and telecommunications cooperation ties with other sectors of the tourism industry is a priority post and telecommunications sector.

Inbound affect the lodging industry in Xinjiang tourism revenue came in second place, the proportion of income ranked third, the development of a more balanced, but the proportion of the lodging industry revenue is only $8.77 \%$. We can see that the tourism sector as a traditional lodging industry contribution of tourism income is low, there is a problem in the lodging industry in Xinjiang

tourism, Xinjiang tourism peak seasons seasons, the off-season to stay idle problem is accommodation and tourism revenue accounted for less one of the factors.

Correlation long distance traffic in third place, ranked second in total revenue, nearly 19\% higher than in third place in the lodging industry. Long-haul traffic demand is less elastic in the tourism industry sectors, but it is indeed a very high proportion of total revenue. This is tantamount to restricting the development of tourism in other sectors, so that the structural imbalance in Xinjiang inbound tourism industry, the development is unreasonable.

Correlation merchandising in fourth place, the proportion of income first 37.2\%. Merchandising industry as the demand elasticity of the tourism industry in the high proportion of industry revenue, indicating merchandising industry in good condition, Xinjiang tourism industry should take advantage of high commodity sales revenue of this factor to pass or drive the development of other sectors of the tourism industry to make tourism the sound development of the industrial structure.

Associated with the income share of the catering industry were ranked sixth and fifth place, the restaurant industry as a traditional inbound tourism sector in the less influential Xinjiang, Xinjiang characteristic food culture does not play its role.

Correlation tour industry ranked eighth, the proportion of revenue $3.83 \%$ tourism, inbound tourism tour industry in Xinjiang's influence is very low. Xinjiang is the country's most abundant 
tourism resources in one area, but no resources into economic advantages, there is no reasonable development of tourism resources and planning, construction and development of scenic spots identical, the lack of quality awareness, more for tickets for economy, is at a low level of malignancy competition.

Entertainment in inbound tourism association of Xinjiang came in the last one, the proportion of income is also the seventh, showing that the entertainment industry in inbound tourism in Xinjiang and underdeveloped, Xinjiang is a multi-ethnic gathering place, a variety of cultures here in the intersection has a unique advantage in terms of tourism and entertainment, the entertainment sector demand elasticity high development potential, Xinjiang tourism industry should become an important part of the structure.

Traffic in the city and other services are low in Xinjiang affect inbound tourism industry, the low income sectors. In the tourism industry, not to the city's transport sector is the main profit sector, but local transportation for tourists is also important auxiliary department, city traffic to optimize the structure of the tourism industry also plays an important role.

\section{Xinjiang tourism industry structure optimization suggestions}

Gray theory to analyze inbound tourism in Xinjiang, Xinjiang tourism industry can be seen in the following problems: uneven development of the industrial structure, the high cost of long-distance transportation, accommodation, dining, tours of traditional tourism activities underdevelopment, tourism e-commerce, digital tourism , tourist information modernization needs to be improved. For the above issues raised following suggestions.

Xinjiang should develop tourism e-commerce and digital travel, using the Internet to build large data covering the region with tourist information website, providing convenient travel information publishing and marketing platform to worldwide travelers. Lodging industry by improving the quality of services provided and the level of diversification, personalized products and services for the guests stay, raise the proportion of the lodging industry in tourism revenue in. Xinjiang appropriate to open direct flights between Central Asia and Europe, European tourists into Xinjiang tourism shorten the flight time, the introduction of the low-cost airline operating under the civil aviation market, reduce transport costs in the market competition. Accelerate the construction of high-speed rail, through Xinjiang and Lanzhou new tier mainland cities to achieve high iron straight as soon as possible. The full realization of Xinjiang seamless link aviation, railway, highway. Especially seamless link major tourist destination and center of the city. Tourist attractions continue to root out merchandise to attract tourists, according to market demand, improve the traditional tourism product development is also necessary to do a good job there are regional ethnic cultural characteristics of tourism souvenirs. Second, we must improve the shopping environment, standardize the market order, ensure the quality of goods. Xinjiang restaurant is more than 10 nationalities work together to create, with typical regional and national character, but scenic attractions and hotels did not appear to be reflected this feature, we should vigorously promote the Xinjiang cuisine, so that customers truly feel on the tongue Xinjiang. Xinjiang should be closely linked to the development of scenic spots in Xinjiang Western culture, Xinjiang's unique tourism resource advantages into economic advantages, based on the development of traditional tourism, to create leisure, health care, expedition, cultural experiences and other tourism projects, and Xinjiang to build a unique advantage to play winter snow travel. At the same time, the traditional tourism projects should increase hands-on interactive entertainment, enhance the entertainment industry's competitiveness in the tourism industry.

\section{References}

[1] Chen Yuying. Some Thoughts on optimizing the structure of tourism industry. Tourism Science. 2000(1):28-30.

[2] Tang Liuxiong. Thoughts on Tourism Economic Research. Journal of Guilin Institute of Tourism. 2000,11(1):20-22.

[3] Luo Mingyi. Economics of Tourism.Beijing: Higher Education Press, 1998. 144-149. 
[4] Wang Dawu, Wei Xiaoan. New Edition Economics of Tourism. Shanghai: Shanghai People's Publishing House, 1998,153.

[5] Lin Nanzhi, Tao Hanjun. Economics of Tourism.Tianjin: Nankai University Press, 2001.220-221。

[6] Tian Li. Economics of Tourism. Beijing: Higher Education Press,2002.

[7] Wang Wei, Lu Lin. Analysis on Shaanxi’s International Tourism Industry Structure. Journal of Anhui Normal University(natural science edition), 2008,31(3). 288-292.

[8] He Ying. Xinjiang Tourism Economic impacting factor study based on gray correlation analysis. Ecological economy, 2012(1), 160-162.

[9] Deng Julong. Grey system theory.Wuhan: Huazhong University of Science and Technology Press,1990.17-43.

[10]Correlation Analysis of Zhangjiajie Tourism Industry Structure Based on Gray Correlation. Tourism Forum,2012,5(6):56-61. 